\title{
Process of Developing the Online Certification Tests for Research Project Trainees and Assessing the Feasibility for Adaptation in Maternal and Child Health Projects
}

\author{
Manoj Patil ${ }^{1}$, Mahlaqua Nazli Khatib², Shilpa Gaidhane ${ }^{3}$, Shital Telrandhe ${ }^{4}$, Deepak Saxena ${ }^{5}$, Unnikrishnan B. ${ }^{6}$ \\ Pankaj Bhardwaj ${ }^{7}$, Abhay M. Gaidhane ${ }^{8}$, Quazi Syed Zahiruddin ${ }^{9}$
}

\begin{abstract}
${ }^{1}$ Department of R\&D, Centre of Excellence School of Epidemiology and Public Health Datta Meghe Institute of Medical Sciences (Deemed to be University), Wardha, Maharashtra, India. ${ }^{2}$ Department of Physiology, Centre of Excellence School of Epidemiology and Public Health Datta Meghe Institute of Medical Sciences (Deemed to be University), Wardha, Maharashtra, India. ${ }^{3}$ Department of Medicine, Datta Meghe Institute of Medical Sciences (Deemed to be University), Wardha, Maharashtra, India. ${ }^{4}$ Department of R\&D, Centre of Excellence School of Epidemiology and Public Health Datta Meghe Institute of Medical Sciences (Deemed to be University), Wardha, Maharashtra, India.

${ }^{5}$ IIPHG, Gandhinagar, Gujarat, India. ${ }^{6}$ Departmetn of Community Medicine, Kasturba Medical College, Manipal

University, Manipal, Karnataka, India. ${ }^{7}$ Department of Community Medicine, AIIMS, Jodhpur, Rajasthan, India. ${ }^{8}$ Department of Community Medicine and Division of Evidence Synthesis, Centre of Excellence School of Epidemiology and Public Health Datta Meghe Institute of Medical Sciences (Deemed to be University), Wardha, Maharashtra, India. ${ }^{9}$ Department of Community Medicine and Division of Evidence Synthesis, Centre of Excellence School of Epidemiology and Public Health Datta Meghe Institute of Medical Sciences (Deemed to be University), Wardha, Maharashtra, India.
\end{abstract}

\section{ABSTRACT}

\section{BACKGROUND}

An innovation launched by Datta Meghe Institute of Medical Sciences emphasized on promoting early child development through govt. Anganwadi centers under the project 'Stepping Stones'. The innovation includes delivery of Enhanced Anganwadi Curriculum and Parenting Sessions through home visits by trained Anganwadi Workers with support from Community Health Workers. A system of computerized online and of training certification test was developed. This paper outlines the results of feasibility and acceptance of this system by Community Health Workers in maternal and child health programs.

\section{METHODS}

Pre-tested questionnaire with questions on different aspects of certification test and responses with Likert-type scoring scale was provided to 30 randomly selected community health workers trained by DMIMS. Weighted means of total scores for agreement/disagreement for feasibility and acceptability questions was calculated.

\section{RESULTS}

Average Weighted Mean of 4.07 demonstrated a strong agreement by all participants towards the feasibility and acceptability of this test. $47.67 \%$ candidates showed strong agreement.

\section{CONCLUSIONS}

Such type of tests can be framed and utilized as, time saving screening, and certification test, for different types of community healthcare cadre.

\section{KEY WORDS}

Certification, Test, Online, Computerized, Community Health Workers, Feasibility, Acceptability
Corresponding Author:

Dr. Mahalaqua Nazli Khatib, Department of Physiology \& Head Division of Evidence Synthesis, Centre of Excellence School of Epidemiology and Public Health, Datta Meghe Institute of Medical Sciences, (Deemed University) Wardha,

Maharashtra, India.

E-mail: nazli.786@rediffmail.com

\section{DOI: $10.14260 /$ jemds/2020/315}

Financial or Other Competing Interests: Dr Khatib Reports Grants from Grand Challenge Canada, Outside the Work.

\section{How to Cite This Article:}

Patil M, Khatib MN, Gaidhane S, et al. Process of developing the online certification tests for research project trainees and assessing the feasibility for adaptation in maternal and child health projects. J. Evolution Med. Dent. Sci. 2020;9(17):1446-1449, $10.14260 /$ jemds $/ 2020 / 315$

Submission 26-12-2019,

Peer Review 11-04-2020,

Acceptance 18-04-2020,

Published 27-04-2020. 


\section{BACKGROUND}

'Stepping Stones' is an ambitious project implemented by DMIMS Wardha with the primary objective of creating innovative model through enhanced Anganwadi program for improving Early Childhood Development in rural areas. In India, Anganwadi Centres under Integrated Child Development Scheme (ICDS) are assigned to provide supplementary nutrition, non-formal preschool education, nutrition and health education and referral services to children under 5 years. ${ }^{(1)}$

Many studies in Wardha district and other rural areas revealed need of improvements in childcare services, the services which are basically delivered by Community health workers. According to a study by Kogade et-al, the practices around early initiation of breastfeeding and exclusive breastfeeding in rural area need to be changed. Also the approach to educate women on IYCF practices need to be comprehensive, socio- culturally acceptable to women from rural area.(2)

As per a study by Khanam et-al, there is enormous difference in MCH services provided to rural and urban areas of Wardha district and post-natal services given to rural areas were very poor. This scenario needs to be changed with equitable service delivery. ${ }^{(3)}$

According to the study by Quazi et-al, challenges for practicing exclusive breast feeding, early initiation and inadequate complementary feeding have long term implication on the cognitive development and this study recommends strengthening Anganwadi program in India with more focus on children under 2 years.(4) Thow et-al recommends for improving multi-sectoral support and coordination and increased clarity regarding roles and responsibilities of frontline workers for interacting with mothers to strengthen IYCF policy at regional level.(5) Puri etal recommends for the integration of IYCF policies into a range of agendas and guidelines related to health and child development service delivery. ${ }^{(6)}$

There is a need of improving the knowledge of all public health and child healthcare professionals on emerging and new infectious diseases so as to control infection related consequences among children.(7) Studies also recommend for effective use of electronic media to encourage health and behavior change, promote the healthy lifestyle, thereby preventing undernutrition in children at a low cost,(8) even some studies recommend state professional councils for maintaining live register of health workers, particularly assigned for malnutrition programmes. ${ }^{(9)}$

The quality of services provided to newborn by health care providers in rural areas are inadequate and need to be improved by strengthening health care providers for counseling services and provide accurate information on various services including prevention of hypothermia, exclusive breast feeding and high risk condition of the baby.(10) The team of dedicated experts from DMIMS is constantly taking efforts to address gaps in healthcare and designing the framework for competency based Public Health Programs.(11)

This project developed enhanced curriculum focused on early childhood development and prepared a tablet PC-based app to enable staff to track child progress and optimize health service utilization. The project involved training of a number of project staff including community health workers (Anganwadi Worker, ASHA, ANM), Data Collectors and Research Assistants. With the aim of developing a Systematic Certification System, a set of these online certification tests was developed. Feasibility and acceptability of these tests among frontline workers was also assessed by analysing the data obtained from a structured questionnaire filled by trainee participants.

\section{About Certification System}

The existing system of conducting certification process is manual with a lot of gaps and drawbacks.(12) The main purpose of this system was to efficiently evaluate the candidate through a fully automated system that is programmed to give fast results and provide certification in a short time. So this fully computerized online certification system was introduced. This system included following steps-

1. Candidate Registration- the candidate needs to enter his details in the registration form.

2. Trial Test- A trial test appears on the screen which includes 15 questions of very easy general terms like "how many eyes do you have?" This is just to ensure that the candidates are able to read and mark the options.

3. Actual Test- On completion of trial test successfully with all answers marked with correct options, the actual test questions are displayed on the screen one by one with options. The side box displays the digits from 1-100 which can be clicked to access that question and mark the answer option. Also Timer keeps flashing on the upper right corner of the screen keeping the participant alerting about the time left.

4. Submission of test- The candidate is supposed to click answers of all 100 questions in 100 minutes time and it will automatically direct to 'submit' the test. If candidate fails to complete all 100 test questions within 100 minutes, the test automatically gets submitted and results are displayed.

5. Results- On completion of 100 minutes time or clicking of answers for all 100 questions, test is submitted and the 'Results window' pops-up which displays the candidates details, time of onset and submission/completion of test, number of questions answered, number of correct answers and wrong answers and total score of the candidate.

The key features of this test include - 1] shuffling of questions from a set of total 500 questions for a particular category of post. 2] Shuffling of options for same individual question for different log-ins. 3] Categories of tests prepared with different levels of difficulties from easiest to toughest. 4] Up to 50 candidates can login and administer this test at the same time from all desktops connected through one IP address. 5] Facility for storage and tracking the record of each examination which makes searching of the records easier.

\section{Test Administration Process and Categories}

The system administrator prepares the tests and allots questions for each certification examination. The candidates can login through the client computers with registration number allotted and can take the test. Administrator will 
assign test and test category to candidate before starting. The questions are shuffled in a random order so that possibilities for getting questions in the same order for the candidates sitting close to each other, is very less. A timer monitors the time and at the completion of time limit, the test gets automatically submitted. Candidates can submit the test before time, if finished and view their result. The results are automatically analysed by the system, saving the quality time needed for invigilation, monitoring and manual correction.

Three categories have been created for the staff certification i.e. CAT-1, CAT- 2 and CAT- 3 . In CAT-1, candidate is allowed to navigate through sections in the test and have the flexibility to change the options they answered before. In CAT-2, candidate is allowed to visit any section in the test but restriction is applied that he/she cannot change the previously answered option. In CAT-3, candidate is neither allowed to navigate randomly through sections nor he/she can revisit questions once answered.

We have sections with questions on the instruments and tools used for specific work profile, related to child development. For example, for Research Assistants assigned with Child development assessments. The test for the Anganwadi workers provided questions in Marathi as Anganwadi workers are not well versed with English version and have problem while understanding the questions.(13) The sections included questions on working pattern of ICDS, different domains of child development, curriculum activities assigned for specified developmental domains, parenting competencies and deliverables at home visits for parenting.

This study was conducted for assessing the feasibility and acceptability of online certification tests for different community/project workers and assessing the scope for generalization of these tests to other govt. programmes.

\section{METHODS}

For this study, the list of 100 CHWs engaged in Community Outreach Program of DMIMS was obtained and 30 candidates were randomly selected. Each candidate was provided with a questionnaire having questions on different aspects of certification test with scoring chart. The scoring chart for each question included scores from 0 to 5 where 0 indicated Strong Disagreement and 5 indicated Strong Agreement for the key point in question list. Each participant was explained the procedure of scoring before filling the form and completely filled forms were obtained back which took an average time of approximately $30 \mathrm{~min}$. Data analysis included calculation of Weighted Means for scores assigned by respondents. Average Weighted Mean was calculated for overall questionnaire scores. Weighted Mean was interpreted as follows:

\begin{tabular}{|cc|}
\hline Score of Weighted Mean & Level of Agreement \\
$<1$ & Strong disagreement \\
$1.1-2.0$ & Slight disagreement \\
$2.1-3.0$ & Slight agreement \\
$3.1-4.0$ & Moderate agreement \\
$>4.0$ & Strong agreement \\
\hline
\end{tabular}

Proportions of respondents were calculated for categories of disagreement, agreement and strong agreement about the key points on different aspects of certification tests.

\section{RESULTS}

Average Weighted Mean of 4.07 demonstrated a strong agreement by all participants towards the feasibility and acceptability of this test (Table 1). $89.7 \%$ participants showed agreement towards the feasibility and acceptability of this test and among them, $47.67 \%$ showed strong agreement whereas only $10.3 \%$ participants showed disagreement (Table 2).

\begin{tabular}{|c|c|c|c|c|c|c|c|}
\hline \multirow{2}{*}{$\begin{array}{c}\text { Questions } \\
\text { (Scores: 0=Strong disagreement; } \\
\text { 5=Strong agreement) }\end{array}$} & \multicolumn{6}{|c|}{$\begin{array}{c}\text { Frequency of Scores } \\
\text { Assigned }\end{array}$} & \multirow[t]{2}{*}{$\begin{array}{l}\text { Weighted } \\
\text { Mean }\end{array}$} \\
\hline & 0 & 1 & 2 & 3 & 4 & 5 & \\
\hline $\begin{array}{c}\text { Easier Login and access to certification } \\
\text { test }\end{array}$ & 0 & 2 & 4 & 7 & 7 & 10 & 3.63 \\
\hline $\begin{array}{l}\text { Questionnaire easy, readable, and } \\
\text { correctly drafted in local language }\end{array}$ & 0 & 0 & 3 & 9 & 4 & 14 & 3.97 \\
\hline $\begin{array}{l}\text { Relevant answer options for objective } \\
\text { questions }\end{array}$ & 0 & 0 & 0 & 1 & 13 & 16 & 4.5 \\
\hline $\begin{array}{c}\text { Easiness of marking answers in } \\
\text { provided time }\end{array}$ & 0 & 0 & 2 & 3 & 10 & 15 & 4.3 \\
\hline $\begin{array}{l}\text { Possibility to attempt all } 100 \text { questions } \\
\text { within allotted time limit }\end{array}$ & 1 & 1 & 3 & 4 & 5 & 16 & 3.97 \\
\hline $\begin{array}{l}\text { Questions covered all major and minor } \\
\text { topics in the training modules }\end{array}$ & 0 & 0 & 0 & 2 & 11 & 17 & 4.5 \\
\hline $\begin{array}{l}\text { Shuffling of questions and options } \\
\text { making the possibility of copying from } \\
\text { neighbouring candidate nearly } \\
\text { impossible }\end{array}$ & 0 & 1 & 3 & 5 & 6 & 15 & 4.03 \\
\hline $\begin{array}{l}\text { Test easy to administer for all } \\
\text { community health workers }\end{array}$ & 0 & 0 & 1 & 8 & 7 & 14 & 4.13 \\
\hline $\begin{array}{l}\text { Results available immediately on } \\
\text { submission of the test }\end{array}$ & 1 & 3 & 3 & 4 & 6 & 13 & 3.67 \\
\hline $\begin{array}{l}\text { Possibility of such tests with graded } \\
\text { difficulty levels be acceptable to all } \\
\text { CHWs }\end{array}$ & 0 & 1 & 2 & 6 & 8 & 13 & 4.0 \\
\hline Average & 0.18 & 0.822 & 2.1 & 4.73 & 7.36 & 13.45 & 4.07 \\
\hline
\end{tabular}

\begin{tabular}{|c|c|c|c|c|c|c|}
\hline \multirow[t]{2}{*}{ Questions } & \multicolumn{2}{|c|}{ Disagree } & \multicolumn{2}{|c|}{ Agree } & \multicolumn{2}{|c|}{$\begin{array}{l}\text { Strongly } \\
\text { Agree }\end{array}$} \\
\hline & $\begin{array}{c}\text { Scores } \\
0-2\end{array}$ & $\%$ & $\begin{array}{c}\text { Scores } \\
3-5\end{array}$ & $\%$ & $\begin{array}{c}\text { Score } \\
5\end{array}$ & $\%$ \\
\hline $\begin{array}{c}\text { (Scores: } 0=\text { Strong disagreement; } \\
5=\text { Strong agreement) }\end{array}$ & 6 & 20 & 24 & 80 & 10 & 33.33 \\
\hline $\begin{array}{l}\text { Easier Login and access to } \\
\text { certification test }\end{array}$ & 3 & 10 & 27 & 90 & 14 & 46.67 \\
\hline $\begin{array}{l}\text { Questionnaire easy, readable, and } \\
\text { correctly drafted in local language }\end{array}$ & 0 & 0 & 30 & 100 & 16 & 53.33 \\
\hline $\begin{array}{l}\text { Relevant answer options for } \\
\text { objective questions }\end{array}$ & 2 & 6.67 & 28 & 93.3 & 15 & 50 \\
\hline $\begin{array}{c}\text { Easiness of marking answers in } \\
\text { provided time }\end{array}$ & 5 & 16.7 & 25 & 83.3 & 16 & 53.33 \\
\hline $\begin{array}{c}\text { Possibility to attempt all } 100 \\
\text { questions within allotted time limit }\end{array}$ & 0 & 0 & 30 & 100 & 17 & 56.67 \\
\hline $\begin{array}{l}\text { Questions covered all major and } \\
\text { minor topics in the training modules }\end{array}$ & 4 & 13.3 & 26 & 86.7 & 15 & 50 \\
\hline $\begin{array}{l}\text { Shuffling of questions and options } \\
\text { making the possibility of copying } \\
\text { from neighbouring candidate nearly } \\
\text { impossible }\end{array}$ & 1 & 3.33 & 29 & 96.7 & 14 & 46.67 \\
\hline $\begin{array}{l}\text { Test easy to administer for all } \\
\text { community health workers }\end{array}$ & 7 & 23.3 & 23 & 76.7 & 13 & 43.33 \\
\hline $\begin{array}{l}\text { Results available immediately on } \\
\text { submission of the test }\end{array}$ & 3 & 10 & 27 & 90 & 13 & 43.33 \\
\hline Total responses & 31 & 10.3 & 269 & 89.7 & 143 & 47.67 \\
\hline $\begin{array}{r}\text { Table 2. Number and Prc } \\
\text { Disagreement, Agreement } \\
\text { Tes }\end{array}$ & porti & $\begin{array}{l}\text { of } P c \\
\text { ong } A \\
\text { ions }\end{array}$ & rticip & 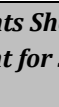 & wing & \\
\hline
\end{tabular}




\section{DISCUSSION}

The online application has been designed for improving quality of Anganwadi workers with advantages over off-line test conduction. In off-line test portal, test conduction is very difficult as compared to online. In off-line test conduction, more man power is required, while online test portal is easy to handle, time savings, provides analysis of the result at any time, and basically transparency can be there about previous results. But Connectivity can be a serious issue of this online certification test. Connection either in an internet cafe or at home can drop at any time for various reasons. Hence this will cause the candidate to inadvertently submit test that is incomplete.

Since, certification program is for the specific users related with the Stepping Stones project, it is not usable for others but can be prepared with the use of this system and main requirement is the questions bank. The project can be converted into such an online exam portal where anyone can use it for their respective needs.

\section{CONCLUSIONS}

This test was found to be quite feasible and well accepted by project workers. This type of test can be made mandatory for all Community Health Workers cadre working in Public Health sector and knowledge on imparted training can be assessed at regular intervals. This will ensure the appropriate quality of services they deliver.

\section{REFERENCES}

[1] Ramachandran V. Reflections on the ICDS programme [cited 2019 Nov 8]. https://www.indiaseminar.com/2005/546/546\%20vimla\%20ramachandr an.htm

[2] Kogade P, Gaidhane A, Choudhari S, et al. Socio-cultural determinants of infant and young child feeding practices in rural India. Medical Science 2019;23(100):1015-22.

[3] Khanam N, Goyal RC, Wagh VG, et al. Quality of maternal and child health, different scenario among rural and urban Maharashtra, India. Int J Curr Biol \& Med Sci 2011;1(3):95-8.
[4] Zahiruddin Q, Gaidhane A, Kogade P, et al. Challenges and Patterns of Complementary Feeding for Women in Employment: A Qualitative Study from Rural India. Curr Res Nutr Food Sci J 2016;2019;4(1):48-53. http://www.foodandnutritionjournal.org/volume4numb er1/challenges-and-patterns-of-complementary-feedingfor-women-in-employment-a-qualita-tive-study-fromrural-india/

[5] Thow AM, Karn S, Devkota MD, et al. Opportunities for strengthening infant and young child feeding policies in South Asia: Insights from the SAIFRN policy analysis project. BMC Public Health 2017;17(Suppl 2):404.

[6] Puri S, Fernandez S, Puranik A, et al. Policy content and stakeholder network analysis for infant and young child feeding in India. BMC Public Health 2019;17(Suppl 2):461.

http://bmcpublichealth.biomedcentral.com/articles/10. 1186/s12889-017-4339-z

[7] Kakkar M, Ramani S, Menon G, et al. 'Zoonoses? Not sure what that is...' An assessment of knowledge of zoonoses among medical students in India. Trans R Soc Trop Med Hyg 2011;105(5):254-61.

[8] Gaidhane AM, Sinha A, Khatib MN, et al. A systematic review on effect of electronic media on diet, exercise and sexual activity among adolescents. Indian J Community Med 2018;43(Suppl 1):S56-S65.

[9] Zodpey S, Sharma A, Zahiruddin QS, et al. Allopathic doctors in India: estimates, norms and projections. J Health Manag 2018;20(2):151-63. http://journals.sagepub.com/doi/10.1177/0972063418 763651

[10] Khanam N, Quazi SZ, Goyal RC, et al. Prospective study on quality of newborn care. Indian Journal of Community Health 2013;25(4):432-7.

[11] Sharma K, Zodpey S, Morgan A, et al. Designing the framework for competency-based master of public health programs in India. Journal of Public Health Management and Practice 2013;19(1):30-9.

[12] Temitayo FM, Adebisi AA, Alice 00. Computer Based Test (CBT) system for University Academic Enterprise Examination. International Journal of Scientific and Technology Research 2013;2(8):336-42.

[13] Meenal TM, Kurll BM, Doibale MK, et al. Knowledge of Anganwadi workers and their problems in an urban ICDS Block. J Med Coll Chandigarh 2011;1(1):15-9. 